\title{
Desenvolvimento de novilhas de corte sob alternativas de mineralização em pastagem de azevém
}

\author{
Development of beef heifers under mineralization alternatives, on Italian ryegrass pasture
}

\author{
Luciana Pötter ${ }^{\mathrm{I}}$ Marta Gomes da Rocha' ${ }^{\mathrm{II}}$ Alexandre Nunes Motta de Souza ${ }^{\mathrm{I}}$ Dalton Roso ${ }^{\mathrm{I}}$ \\ Carine Lisete Glienke ${ }^{\mathrm{I}}$ Vagner Guasso da Costa ${ }^{\mathrm{I}}$ Renato Alves de Oliveira Neto ${ }^{\text {III }}$ \\ Gustavo Freitas Ilha ${ }^{\mathrm{V}}$
}

\section{RESUMO}

Foi avaliado o desenvolvimento corporal de bezerras de corte em pastagem de azevém (Lolium multiflorum Lam.), recebendo diferentes alternativas de suplementação mineral, associadas ou não à adição de ionóforo. Os tratamentos testados foram: "Sal comum": mineralização com cloreto de sódio; "Sal 40P": mineralização com sal mineral contendo $40 \mathrm{~g}$ de fósforo por $\mathrm{kg}$ de produto; "Sal $40 \mathrm{P}+$ ionóforo": mineralização com $40 \mathrm{~g}$ de fósforo $+2.000 \mathrm{mg}$ de lasalocida sódica por $\mathrm{kg}$ de produto. Os valores de proteína bruta, fibra em detergente neutro, Ca e $P$ na forragem aparentemente consumida, consumo de sal, escore de condição corporal, relação peso: altura e GMD foram semelhantes $(P>0,05)$ entre animais que receberam "Sal comum", "Sal $40 P$ " $e$ "Sal 40P + ionóforo". Em pastagem de azevém, sem restrição ao consumo voluntário, a lasalocida sódica adicionada ao sal mineral proporciona maior peso vivo de bezerras aos 12 meses de idade e um retorno financeiro positivo.

Palavras-chave: cloreto de sódio, ionóforo, lasalocida sódica, sal mineral.

\section{ABSTRACT}

Body development of beef heifers grazing Italian ryegrass pasture (Lolium multiflorum Lam.) was evaluated. The animals received different alternatives of mineral supplement: associated or not to ionophore addition and the treatments were: 'Common salt': mineralization with sodium chloride; '40P salt': mineralization with mineral salt plus $40 \mathrm{~g}$ of phosphorus per kilo of product; 40P salt + ionophore: mineralization with $40 \mathrm{~g}$ of phosphorus plus $2000 \mathrm{mg}$ of lasalocid per $\mathrm{kg}$ of product. The values of crude protein, neutral detergent fiber and $\mathrm{Ca}$ and $\mathrm{P}$ of the apparently consumed forage, salt intake, body condition and body weight:height relation were similar $(P>0.05)$ between animals receiving 'common salt', ' $40 \mathrm{P}$ salt' and ' $40 \mathrm{P}$ salt+ionophor'. For beef heifers grazing ryegrass pasture without intake restriction, the lasalocid associated to mineral salt provides a greater body weight at twelve months age and a positive financial.

Key words: ionophor, lasalocid, mineral salt, sodium chloride.

\section{INTRODUÇÃO}

A utilização de pastagens de estação fria para melhorar o desempenho de fêmeas bovinas de corte em recria é prática usual no Estado do Rio Grande do Sul (RS). Em decorrência da sua facilidade de implantação em áreas de resteva de lavouras e da adaptação a diferentes solos, o azevém (Lolium multiflorum Lam.) é a gramínea hibernal mais utilizada nos sistemas de produção de bovinos de corte.

No RS, de uma forma em geral, os solos são pobres em fósforo, e as plantas que vegetam nesses solos também possuem quantidades insatisfatórios desse mineral, não atendendo as exigências da maioria das categorias de bovinos de corte (BARCELLOS et al., 2003). Assim, geralmente há necessidade de incluir fosfatos na mistura mineral fornecida para bovinos em pastejo (TOKARNIA et al., 1988). Para bovinos em crescimento, em pastejo em forrageiras de clima temperado, como o azevém, existe pouca informação

IPrograma de Pós-graduação em Zootecnia, Universidade Federal de Santa Maria (UFSM). Santa Maria, RS, Brasil.

IIDepartamento de Zootecnia, UFSM, Camobi, 97105-900, Santa Maria, RS, Brasil. E-mail: mgdarocha@gmail.com. Autor para correspondência.

IIICurso de Zootecnia, UFSM, Santa Maria, RS, Brasil.

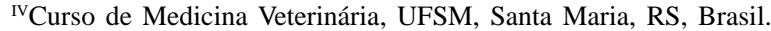


no que diz respeito ao nível de mineralização a ser utilizado.

Para melhorar a eficiência alimentar dos animais em pastejo e proporcionar incrementos no desempenho, são utilizados aditivos nas dietas. Dentre os aditivos mais utilizados, estão os ionóforos, que possuem ação sobre a população microbiana do rúmen, alterando as proporções finais de ácidos graxos voláteis, principalmente pelo aumento na proporção de ácido propiônico e pela diminuição de ácido acético e butírico (RICHARDSON et al., 1976).

A idade à puberdade em novilhas está diretamente relacionada ao peso e à composição corporal. Novilhas que consomem maior quantidade de energia e apresentam maior taxa de ganho de peso diário atingem a puberdade com menor idade (FERREL, 1991). Os ionóforos, quando fornecidos para novilhas de corte, proporcionam maior produção de ácido propiônico e incremento na produção de energia da dieta pela maior produção de glicose. Esses mecanismos estão relacionados com a manifestação precoce da puberdade em novilhas de corte (SCHILLO et al., 1992).

O objetivo deste experimento foi avaliar o desenvolvimento corporal de novilhas de corte em pastagem de azevém, recebendo diferentes alternativas de suplementação mineral associadas ou não à adição de ionóforo.

\section{MATERIAL E MÉTODOS}

O experimento foi conduzido em Santa Maria, Rio Grande do Sul, em área pertencente ao Departamento de Zootecnia, da Universidade Federal de Santa Maria (UFSM), situada na Depressão Central do Estado, com altitude de 95m acima do nível do mar, latitude $29^{\circ} 43^{\prime}$ ' Sul e longitude $53^{\circ} 42^{\prime}$ ' Oeste.

O solo da área experimental pertence à unidade de mapeamento São Pedro e foi classificado como Argissolo Vermelho distrófico arênico, apresentando relevo levemente ondulado, com solos profundos e textura superficial arenosa, bem drenados e naturalmente ácidos. O clima da região é Cfa (subtropical úmido), conforme classificação de Köppen. Os dados médios da análise química do solo da área experimental são: $\mathrm{pH}$ - água: 4,8; $\mathrm{Ca}\left(\mathrm{cmolC} / \mathrm{dm}^{3}\right): 2,6 ; \mathrm{Mg}(\mathrm{cmolC}$ $\left.\mathrm{dm}^{-3}\right)$ : 2,5; $\mathrm{Al}\left(\mathrm{cmolC} \mathrm{dm}^{-3}\right)$ : 0,9; CTC efetiva $\left(\mathrm{cmolC} \mathrm{dm}^{-3}\right)$ : 7,0; CTC pH 7,0 (cmolC dm-3): 16,8; Saturação Al (\%) : 15,4; Saturação Bases (\%) : 42,6; Índice SMP : 5,3; MO (\%): 3,0; P (mg dm$\left.{ }^{-3}\right): 4,7$ e K (mg dm$\left.{ }^{-3}\right): 57$.

A área utilizada tem 4,5ha, com seis subdivisões de 0,75 ha e uma área contígua para permanência dos animais reguladores. A pastagem foi estabelecida por semeadura a lanço, em 03 de maio de
2006, com preparo do solo pelo sistema convencional. Foram utilizados $30 \mathrm{~kg} \mathrm{ha}^{-1}$ de semente de azevém, com adubação na base de $100 \mathrm{~kg} \mathrm{ha}^{-1}$ de NPK (5-20-20) e $67,7 \mathrm{~kg} \mathrm{ha}^{-1}$ de nitrogênio, em cobertura, na forma de uréia, em três aplicações. O período experimental iniciou em 25 de julho, estendendo-se até 18 de outubro de 2006, totalizando 84 dias. O método de pastejo foi o contínuo, utilizando-se três novilhas para testes e um número variável de reguladoras por repetição, para manter a massa de forragem (MF) entre 1.200 e $1.800 \mathrm{~kg}$ ha $^{-1}$ de MS. Para retirar o efeito do piquete, durante o período experimental, os animais realizaram rotação nas subdivisões a cada 21 dias.

Com novilhas da raça Charolês e cruzas com Nelore em pastejo em azevém (Lolium multiflorum Lam.), que apresentavam em julho de 2006 idade de nove meses e PV médio de 166,4kg, os tratamentos testados foram: "Sal comum": mineralização com cloreto de sódio; "Sal 40P”: mineralização com sal mineral contendo $40 \mathrm{~g}$ de fósforo por kg de produto; "Sal 40P + ionóforo”: mineralização com $40 \mathrm{~g}$ de fósforo + 2.000mg de lasalocida sódica por kg de produto.

O suplemento mineral utilizado foi fornecido à vontade, com reposição realizada duas vezes por semana e apresentava como fonte de fósforo o fosfato bicálcico. Nos dias de reposição, a quantidade disponível no cocho era pesada, após secagem em estufa de circulação de ar forçada a $60^{\circ} \mathrm{C}$, assim como o novo fornecimento.

Para a determinação da massa de forragem (MF), foi utilizada a técnica de estimativa visual com dupla amostragem, realizada a cada 10 dias, e a MF foi calculada por equação de regressão entre as estimativas visuais e cortadas. A taxa de acumulação diária de MS foi determinada utilizando-se três gaiolas de exclusão ao pastejo por unidade experimental (WILM et al., 1944).

A carga animal (CA), por período, foi calculada por meio da soma do peso médio dos animaisteste mais o peso dos animais reguladores, multiplicado pelo número de dias que estes permaneceram na pastagem. O produto foi dividido pelo número de dias do período de pastejo, sendo expressa em $\mathrm{kg} \mathrm{ha}^{-1}$ de peso vivo (PV).

Por meio da técnica da simulação de pastejo, foram tomadas amostras de forragem para determinação das características químicas do pasto (EUCLIDES et al., 1992). Foi avaliado o teor de fibra em detergente neutro (TILEY \& TERRY, 1963) e o teor de N total, determinado pelo método micro Kjedahl (AOAC, 1995). Os teores de $\mathrm{Ca}$ e $\mathrm{P}$ foram determinados com espectofotômetro de absorção atômica e por colorimetria, respectivamente (SILVA \& QUEIROZ, 2002). 
As pesagens dos animais foram realizadas com intervalo médio de 21 dias, respeitando jejum prévio de sólidos e líquidos de 12 horas. Por ocasião das pesagens, os animais eram submetidos a uma avaliação subjetiva da condição corporal (ECC, 1-5), em que o escore 1,0 representava animais muito magros e o escore 5,0, animais muito gordos (LOWMANN et al., 1976). O ganho de peso médio diário (GMD) dos animais foi obtido pela diferença entre peso final e inicial dos animais-teste em cada período experimental, dividido pelo número de dias do período. As medidas de altura dos animais, inicial (nove meses de idade) e final (12 meses de idade) foram efetuadas na região da garupa com o auxílio de uma bengala de Thompson.

A avaliação econômica foi realizada com a utilização de planilhas de cálculo do Microsoft Excel ${ }^{\circledR}$, versão 2000, segundo modelo proposto por PÖTTER et al. (1998). Os preços utilizados para o cálculo dos custos totais foram obtidos a partir de uma pesquisa de mercado efetuada em maio de 2008, na região de Santa Maria, RS.

O delineamento experimental utilizado foi o inteiramente casualizado, com parcelas subdivididas no tempo, com duas repetições de área (potreiros). As variáveis estudadas foram submetidas à análise de variância dos dados e ao teste $\mathrm{F}$ em nível de foram 5\% de significância. Foi realizado o teste Tukey quando detectadas diferenças entre tratamentos e/ou períodos. Foi realizada a análise de contrastes testando a utilização ou não do ionóforo. As variáveis foram submetidas à análise de regressão para os dias de pastejo, com ajuste do modelo polinomial até terceira ordem. As análises foram efetuadas pelo procedimento GLM (General Linear Model) do programa estatístico SAS, versão 8.2 (SAS, 2001).

\section{RESULTADOS E DISCUSSÃO}

A tabela 1 apresenta os valores médios para carga animal (CA), massa de forragem (MF), taxa de acúmulo diário de forragem (TAD), oferta de forragem (OF), teor de proteína bruta (PB), fibra em detergente neutro (FDN), cálcio (Ca) e fósforo (P) da forragem proveniente da simulação de pastejo, consumo diário de suplemento mineral (consumo de sal) e ganho de peso médio diário (GMD) de novilhas em azevém mineralizadas com "Sal comum”, "Sal 40P” e "Sal 40P + ionóforo".

As variáveis relacionadas à produção da pastagem (CA, MF, TAD e OF) são apenas descritivas devido ao rodízio dos animais realizado entre os piquetes, não sendo realizada análise estatística. Os valores de PB, FDN, Ca e P na forragem aparentemente consumida, no consumo de sal e no GMD foram semelhantes $(\mathrm{P}>0,05)$ entre novilhas recebendo "Sal comum”, "Sal 40P” ou "Sal 40P + ionóforo".

A quantidade de produto mineral consumida pelos animais foi semelhante $(\mathrm{P}>0,05)$ entre as diferentes fontes de mineralização (Tabela 1), com média de consumo correspondendo a $0,012 \%$ do PV. Esse consumo, considerando os níveis de garantia dos produtos utilizados, proporcionou uma suplementação adicional de $3,2 \mathrm{~g} \mathrm{dia}{ }^{-1}$ de cálcio e $1,1 \mathrm{~g} \mathrm{dia}^{-1}$ de fósforo no tratamento sal 40P; 3,2g dia-1 de cálcio, $1,1 \mathrm{~g} \mathrm{dia}^{-1}$ de

Tabela 1 - Valores médios de carga animal, $\mathrm{kg} \mathrm{ha}^{-1}$ de peso vivo (PV), massa de forragem, $\mathrm{kg} \mathrm{ha}^{-1}$ de MS, taxa de acúmulo diário de

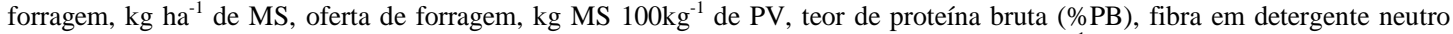
$(\% \mathrm{FDN})$, cálcio $(\% \mathrm{Ca})$ e fósforo $(\% \mathrm{P})$ da forragem, consumo de suplemento mineral, g dia ${ }^{-1}$, e ganho de peso médio diário (GMD, $\mathrm{kg} \mathrm{dia}^{-1}$ ) de novilhas mantidas em pastagem de azevém mineralizadas com sal comum, sal mineral contendo 40g de fósforo por $\mathrm{kg}$ de produto ou sal mineral com $40 \mathrm{~g}$ de fósforo por $\mathrm{kg}$ de produto + lasalocida sódica.

\begin{tabular}{|c|c|c|c|c|c|}
\hline \multirow{2}{*}{ Características avaliadas } & \multicolumn{4}{|c|}{-------------------------Períodos de avaliação-------------------------- } & \multirow[b]{2}{*}{ Médias } \\
\hline & 25/07-15/08 & $16 / 08-05 / 09$ & 06/09-25/09 & 26/09-18/10 & \\
\hline Carga animal & 744,7 & 761,1 & 832,3 & 1162,0 & 875,1 \\
\hline Massa de forragem & 1218,7 & 1395,5 & 1936,7 & 2259,7 & 1702,7 \\
\hline Taxa de acúmulo diário de forragem & 30,1 & 31,3 & 64,9 & 41,3 & 42,1 \\
\hline Oferta de forragem & 13,3 & 14,4 & 19,8 & 13,1 & 14,5 \\
\hline$\% \mathrm{~PB}$ & 26,5 & 25,7 & 27,5 & 21,2 & $25,2 \mathrm{~ns}$ \\
\hline$\% \mathrm{FDN}$ & 41,4 & 27,4 & 32,8 & 39,5 & $35,5 \mathrm{~ns}$ \\
\hline$\% \mathrm{Ca}$ & 0,60 & 0,60 & 0,60 & 0,50 & $0,58 \mathrm{~ns}$ \\
\hline$\% \mathrm{P}$ & 0,34 & 0,20 & 0,29 & 0,26 & $0,27 \mathrm{~ns}$ \\
\hline Consumo de suplemento mineral & 26,4 & 24,1 & 30,5 & 24,1 & $26,3 \mathrm{~ns}$ \\
\hline GMD & 0,989 & 1,098 & 1,122 & 1,046 & $1,064 \mathrm{~ns}$ \\
\hline
\end{tabular}

ns $=\mathrm{P}>0,05$ 
fósforo e $53 \mathrm{mg}$ dia $^{-1}$ de lasalocida sódica no tratamento Sal 40P + ionóforo. Essa suplementação adicional de Ca e $\mathrm{P}$ não afetou $(\mathrm{P}>0,05)$ o ganho médio diário das novilhas porque as exigências para o ganho realizado já haviam sido supridas pelo consumo de azevém. As exigências nutricionais citadas pelo Nutrient Research Council - NRC (1996), para fêmeas bovinas de corte com $200 \mathrm{~kg}$ de $\mathrm{PV}$, ganho de $1,0 \mathrm{~kg} \mathrm{dia}^{-1}$ e consumo de 5,4kg de MS dia-1 ${ }^{-1}$ são de 0,672kg de PB, 29g de cálcio (Ca) e $15 \mathrm{~g}$ de fósforo (P). Considerando os valores percentuais de $\mathrm{PB}$, Ca e $\mathrm{P}$ (Tabela 1 ), medidos no pasto aparentemente consumido pelas novilhas e a estimativa de consumo diário de MS para o ganho realizado, o azevém exclusivo forneceu aos animais $1,36 \mathrm{~kg}$ de $\mathrm{PB}$, $31 \mathrm{~g}$ de Ca e $15 \mathrm{~g}$ de P. As quantidades de Ca e P consumidas exclusivamente com o pasto, quando confrontadas com as exigências para essa categoria, foram adequadas para o GMD realizado pelas novilhas, $1,064 \mathrm{~kg} \mathrm{dia}^{-1}$, que não diferiu entre as novilhas que receberam diferentes mineralizações $(\mathrm{P}>0,05)$. Esse resultado pode ser atribuído ao manejo da pastagem de azevém, o qual assegurou valores de massa e oferta de forragem (Tabela 1) que permitiram que as novilhas em pastejo selecionassem uma dieta com quantidade e composição para atender as exigências nutricionais para ganho de 1,0kg dia-1. Em pastejo, quando há oportunidade para que os animais exerçam sua seletividade, o material preferencialmente consumido são as lâminas foliares do pasto, com maior conteúdo de $\mathrm{N}$ e minerais. Além disoo, o valor de FDN no pasto consumido (Tabela 1), considerado por MERTENS (1992) como o melhor indicador do potencial de consumo dos alimentos para os ruminantes foi inferior ao valor de 55-60\%, considerado como limitante do consumo (VAN SOEST, 1994).

$\mathrm{Na}$ tabela 2 são apresentados os valores observados no início e fim do experimento para PV, CC, e relação entre peso vivo e altura $(\mathrm{P}: \mathrm{H})$ das novilhas em azevém mineralizadas com "Sal comum”, "Sal 40P" ou "Sal 40P + ionóforo". Não houve interação entre tratamento e período e nem diferença $(\mathrm{P}>0,05)$ entre animais com diferentes mineralizações para as variáveis PV, CC e relação P:H.

Fêmeas bovinas atingem, geralmente, a altura adulta antes do peso adulto, sendo este o principal determinante da adequada relação P:H. A relação P:H média verificada para as novilhas aos 12 meses de idade foi de $2,12 \mathrm{~kg} \mathrm{~cm}^{-1}$, inferior à relação considerada adequada para manifestação da puberdade de novilhas aos 426 dias de idade, que é de $2,53 \mathrm{~kg} \mathrm{~cm}^{-1}$ (FOX et al., 1988).

MACARI (2005), avaliando novilhas do mesmo rebanho dos animais do presente experimento aos 18 meses de idade, observou uma relação P:H média de $2,30 \mathrm{~kg} \mathrm{~cm}^{-1}$. Essas novilhas, exclusivamente em pastejo em azevém, apresentaram relação P:H de 2,13kg $\mathrm{cm}^{-1}$ e novilhas que receberam $0,9 \%$ do PV de suplemento energético, relação P:H de $2,46 \mathrm{~kg} \mathrm{~cm}^{-1}$. Essa maior relação P:H das novilhas suplementadas ocorreu devido a uma diferença de 38,7kg no PV, pois a altura dos animais, em ambos os sistemas de alimentação, foi de $116 \mathrm{~cm}$.

O estudo de contrastes entre animais que receberam e não receberam lasalocida mostrou que a suplementação mineral com adição de ionóforo influenciou positivamente o peso vivo dos animais $(\mathrm{P}<0,05)$ aos 12 meses de idade. A evolução do peso vivo no decorrer do período experimental ajustou-se ao modelo de regressão linear crescente (Figura 1). A mineralização das novilhas com adição de ionóforo permitiu um ganho de $1,15 \mathrm{~kg}$ de $P V$ dia $^{-1}$ de utilização da pastagem, enquanto as fêmeas que receberam sal comum ou sal 40P sem adição de ionóforo atingiram um ganho de $1,06 \mathrm{~kg}$ de $\mathrm{PV}$ dia $^{-1}$ de utilização da pastagem, respectivamente. O ganho adicional das novilhas que receberam ionóforo correspondeu a $0,09 \mathrm{~kg}$ de PV dia ${ }^{-1}$. Admitindo o peso adulto de $450 \mathrm{~kg}$ para essas fêmeas, o peso-alvo para manifestação da

Tabela 2 - Relação peso vivo:altura (P:H), peso vivo (PV) e escore de condição corporal (ECC) aos nove meses (9M) e doze meses (12M) de idade, de novilhas mantidas em pastagem de azevém mineralizadas com sal comum, sal mineral contendo 40 gramas de fósforo por kg de produto ou sal mineral com 40 gramas de fósforo por kg de produto + lasalocida sódica.

\begin{tabular}{|c|c|c|c|c|c|c|}
\hline \multirow[b]{2}{*}{ Tratamentos } & \multicolumn{2}{|c|}{$\mathrm{P}: \mathrm{H}\left(\mathrm{kg} \mathrm{cm}^{-1}\right)$} & \multicolumn{2}{|c|}{ PV (kg) } & \multicolumn{2}{|c|}{ ECC (1-5, pontos) } \\
\hline & $9 \mathrm{M}$ & $12 \mathrm{M}$ & $9 \mathrm{M}$ & $12 \mathrm{M}$ & $9 \mathrm{M}$ & $12 \mathrm{M}$ \\
\hline Sal comum & 1,51 & 2,11 & 165,75 & 253,67 & 2,33 & 2,93 \\
\hline Sal 40P & 1,48 & 2,11 & 165,83 & 253,84 & 2,33 & 2,87 \\
\hline Sal 40P + ionóforo & 1,52 & 2,16 & 167,67 & 262,50 & 2,30 & 2,92 \\
\hline Médias & $1,50 \mathrm{~B}$ & $2,14 \mathrm{~A}$ & $166,47 \mathrm{~B}$ & $256,75 \mathrm{~A}$ & $2,32 \mathrm{~B}$ & $2,96 \mathrm{~A}$ \\
\hline Desvio padrão & $\pm 0,03$ & $\pm 0,06$ & $\pm 3,59$ & $\pm 8,75$ & $\pm 0,04$ & $\pm 0,05$ \\
\hline
\end{tabular}

Médias seguidas de letras maiúsculas na coluna diferem entre si $(\mathrm{P}<0,05)$ pelo teste Tukey.

Ciência Rural, v.39, n.1, jan-fev, 2009. 


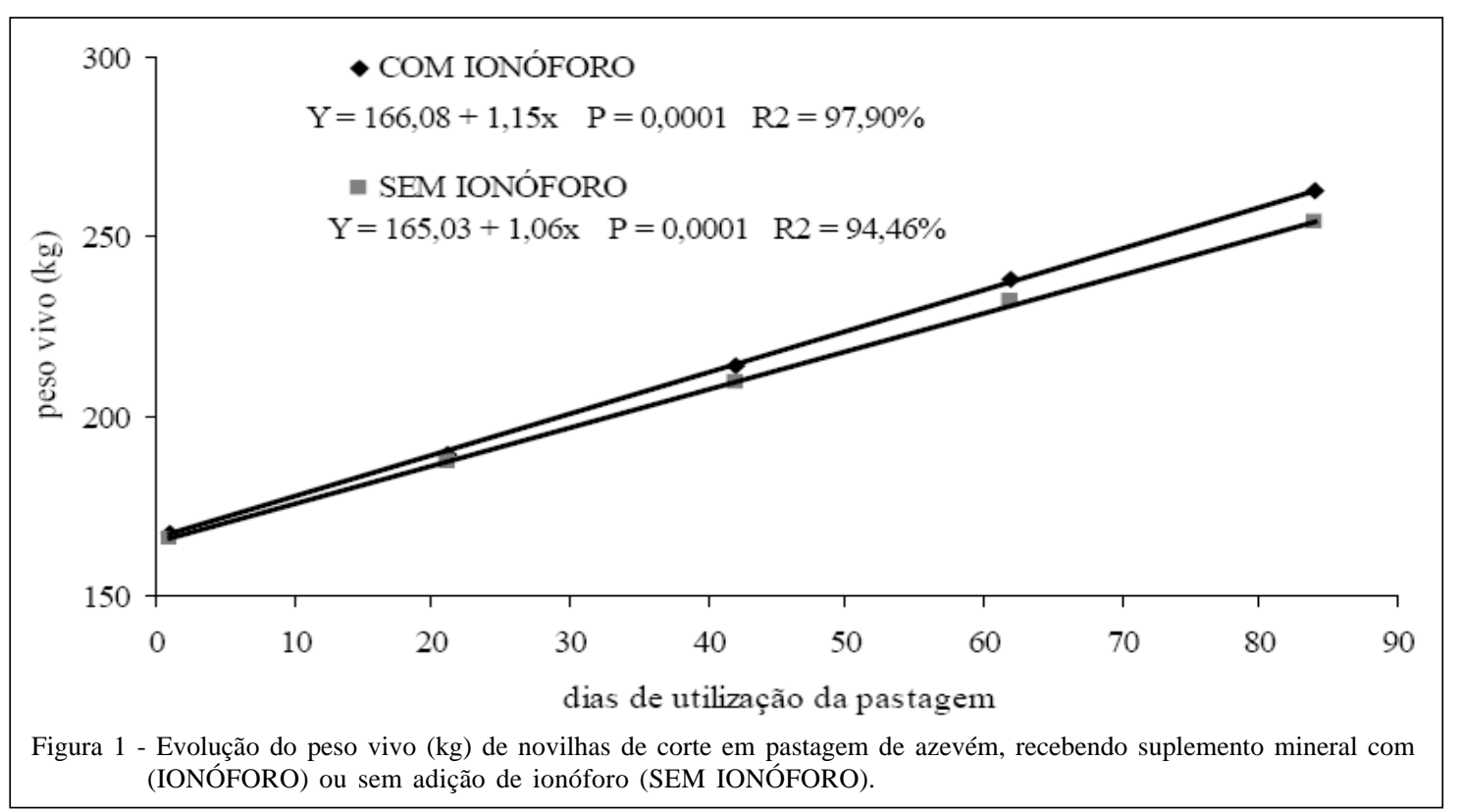

puberdade, 293kg, seria atingido 10 dias antes quando mineralizadas com adição de ionóforo. Incrementos de 4,9\% no ganho de peso e de 7,9\% na eficiência alimentar são citados por STOCK et al. (1995) para animais em crescimento mantidos em confinamento e recebendo ionóforo.

Para serem logrados bons índices de prenhez ao primeiro acasalamento, no entanto, o peso alvo para manifestação da puberdade, correspondendo a $65 \%$ do peso adulto, deve ser atingido antes do início do período de acasalamento (ROCHA \& LOBATO, 2002). Para as novilhas do presente experimento, isso inviabilizaria o seu acasalamento aos 13-14 meses de idade, pois elas apresentaram em $18 / 10$ peso correspondente a 58,33 e 56,38\% do peso adulto, quando receberam suplementação com e sem ionóforo, respectivamente. Considerando que novilhas dessa composição racial precisam de $293 \mathrm{~kg}$ para atingir a puberdade, seria necessário um GMD do nascimento aos 12-13 meses de idade em torno de $0,666 \mathrm{~kg} \mathrm{dia}^{-1}$ (peso ao nascer de $40 \mathrm{~kg}$ e 380 dias de idade). O desempenho no período de utilização da pastagem foi acima desse desempenho, no entanto, o baixo peso aos nove meses de idade foi o fator limitante para seu acasalamento aos 13-14 meses de idade.

O custo por hectare da pastagem adicionado de mão-de-obra adicional e despesas com arrendamento totalizou R\$ 508,72. O custo adicional por hectare (referente à suplementação mineral utilizada), correspondeu respectivamente a R \$3,22, R \$ 7,74 e R\$ 9,66 para “Sal comum”, "Sal 40P” e “Sal40P + ionóforo”.
O custo com mineralização por animal correspondeu respectivamente a $\mathrm{R} \$ 0,78, \mathrm{R}$ \$ 1,89 e R \$ 2,35 para “Sal comum”, "Sal 40P” e "Sal40P + ionóforo". O ganho adicional dos animais que receberam ionóforo foi equivalente a $\mathrm{R} \$ 18,14$ no decorrer do período experimental, e o custo adicional em relação ao sal comum foi de R\$1,57, o que justifica a utilização do ionóforo.

\section{CONCLUSÕES}

Quando não existe restrição ao consumo, a pastagem de azevém atende as exigências nutricionais de novilhas de corte dos nove aos 12 meses de idade para ganho de $1 \mathrm{~kg}$ de peso vivo $\mathrm{dia}^{-1}$, independentemente da mineralização utilizada para os animais em pastejo. O fornecimento de lasalocida sódica proporciona maior peso vivo para novilhas aos 12 meses de idade com retorno financeiro à introdução do ionóforo.

\section{REFERÊNCIAS}

ASSOCIATION OF OFFICIAL ANALYTICAL CHEMISTSAOAC. Official methods of analysis. 14.ed. Washington, 1995. 1141p.

BARCELLOS, J.O.J. et al. Suplementação mineral de bovinos de corte em ambientes subtropicais. In: BARCELLOS, J.O.J. et al. Suplementação mineral de bovinos de corte em regiões subtropicais. Porto Alegre: UFRGS, 2003. p.19-52.

EUCLIDES, V.P.B. et al. Avaliação de diferentes métodos de amostragem sob pastejo. Revista Brasileira de Zootecnia, v.21, n.4, p.691-702, 1992.

Ciência Rural, v.39, n.1, jan-fev, 2009. 
FERREL, C.L. Nutritional influences on reproduction. In: CUPPS, P.T. Reproduction in Domestic Animals. 4.ed. San Diego: Academic, 1991. p.577-603.

FOX, D.G. et al. Adjusting nutrient requirementes of beef cattle for animal and environmental variations. Journal Animal Science, v.66, n.5, p.1475-1453, 1988.

LOWMAN, B.G. et al. Condition scoring beef cattle. Edinburgh: East of Scotland College of Agriculture, 1976. 8p. (Bulletin 6).

MACARI, S. Recria de fêmeas de corte para o acasalameto aos 18 meses de idade. 2005. 97f. Dissertação (Mestrado em Zootecnia) - Curso de Pós-graduação em Zootecnia, Universidade Federal de Santa Maria.

MERTENS, D.R. Análise da fibra e sua utilização na avaliação de alimentos e formulação de rações. In: SIMPÓSIO INTERNACIONAL DE RUMINANTES; REUNIÃO ANUAL DA SOCIEDADE BRASILEIRA DE ZOOTECNIA, 29., 1992, Lavras, MG. Anais... Lavras: SBZ, 1992. p.188-219.

NRC - NATIONAL RESEARCH COUNCIL. Nutrient requirement of beef cattle. 7.ed. Washington: National Academy, 1996. 242p.

PÖTTER, L. et al. Produtividade de um modelo de produção de para novilhas de corte primíparas aos dois, três e quatro anos de idade. Revista Brasileira de Zootecnia, v.27, n.3, p.613619, 1998.

RICHARDSON, L.F. et al. Effect of monensin on rumen fermentation in vitro and in vivo. Journal of Animal Science, v.43, n.3, p.657-664, 1976.
ROCHA, M.G.; LOBATO, J.F.P. Sistemas de alimentação pósdesmama de novilhas de corte para acasalamento 14/15 meses de idade. Revista Brasileira de Zootecnia, v.31, n.4, p.18141822, 2002.

SAS. Statistical analysis system user's guide: statistics. Version 8.2. Cary: Statistical Analysis System Institute, 2001. 1686p.

SCHILLO, K.K. et al. Effects of nutrition and season the onset of puberty in beef heifer. Journal Animal Science, v.70, n.12, p.3994-4005, 1992.

SILVA, J.S.; QUEIROZ, A.C. Análise de alimentos: métodos químicos e biológicos. 3.ed. Viçosa: UFV, 2002. 235p.

STOCK, R.A. et al. Effect of monensin and monensin and tylosin combination on feed intake variation of feedlot steers. Journal of Animal Science, v.73, n.1, p.39-44, 1995.

TOKARNIA, C.H. et al. Situação atual e perspectivas da investigação sobre nutrição mineral em bovinos no Brasil. Pesquisa Agropecuária Brasileira, n.1 e 2, p.1-16, 1988.

TILLEY, J.M.A.; TERRY, R.A. A two-stage technique for the "in vitro" digestion of forage crops. Journal British Grassland Society, v.18, n.2, p.104-111, 1963.

VAN SOEST, P.J. Nutritional ecology of the ruminant. 2.ed. Ithaca: Cornell University, 1994. 476p.

WILM, H.G. et al. Estimating forage yield by the doublesampling methods. Journal American Society Agronomy. n.36, p.194-203. 1944. 